Working from home, wages, and regional inequality in the light of COVID-19

by

Michael IRLACHER

Michael $\mathrm{KOCH}$

Working Paper No. 2008

April 2020

Johannes Kepler University of Linz

Department of Economics

Altenberger Strasse 69

A-4040 Linz - Auhof, Austria

www.econ.jku.at

michael.irlacher@jku.at 


\title{
Working from home, wages, and regional inequality in the light of COVID-19 *
}

\author{
Michael Irlacher \\ JKU Linz and CESifo ${ }^{\dagger}$
}

\author{
Michael Koch \\ Aarhus University ${ }^{\ddagger}$
}

9th April 2020

\begin{abstract}
We use the most recent wave of the German Qualifications and Career Survey and reveal a substantial wage premium in a Mincer regression for workers performing their job from home. The premium persists within narrowly defined jobs and after controlling for workplace activities and accounts to more then $10 \%$. In a next step, we provide evidence on substantial regional variation in the share of jobs that can be done from home across NUTS2 districts in Germany. Our results suggest that the COVID-19 crisis might affect already poorer regions more heavily as a lower share of workers can work from home there. Hence, looking at regional disparities in terms of different types of occupations is central for policy makers in choosing the right economic policies to mitigate the consequences of the crisis.
\end{abstract}

JEL codes: J31, J22, J61, R10

Keywords: Working from home, COVID-19, Regional disparities, Home office, BIBB-BAuA

*Financial support by the Carlsberg Foundation is gratefully acknowledged.

${ }^{\dagger}$ Department of Economics, JKU Linz; e-mail: michael.irlacher@jku.at

${ }^{\ddagger}$ Department of Economics and Business Economics, Aarhus University; e-mail: mkoch@econ.au.dk 


\section{Introduction}

Recently, the World Health Organization has declared the outbreak of the coronavirus a pandemic. The number of confirmed cases is still rising dramatically and the human costs of the coronavirus in terms of sick and deceased people are already enormous. Since there is no treatment or vaccine option now, the most effective way of fighting the virus is social distancing. Almost all countries in the world adopted "stay at home" policies, which affect people in many ways and in particular in their daily working routine. Obviously, working in strict accordance with social distancing is easier in jobs that can be carried out at home. However, a large share of workers have jobs where working at home is not feasible in particular if the job requires personal proximity or special equipment and machines. Given the fact that working from home is not an option for every worker, the corona crisis is very likely to affect workers in differential intensities. Many countries report a dramatically increase in unemployment rates in the first week after the economic shutdown and economies with a pronounced welfare state such as Germany or Austria record millions of requests for short-time allowances.

In this paper, we use the latest wave of the German Qualifications and Career Survey (BIBB$\mathrm{BAuA}$ ) to investigate, whether there is a systematical difference in wages between jobs with and without the opportunity to work from home. Given that we plausibly assume that the recent crisis hurts more those jobs that cannot be conducted at home, it is important to know whether these workers were already disadvantaged before the crisis. If this would be the case, the current crisis with all its job losses and income cuts through short-time allowances would further increase income inequality between workers. ${ }^{1}$ Moreover, the crisis could also increase regional inequalities if the share of jobs that can be done from home is unequally distributed across a country. Given these concerns, we want to ask the following questions: Is there a wage premium for jobs that are feasible for home work? What is the share of jobs that can be done from home in Germany? What is the regional variation in this share across NUTS2 districts in Germany? Finally, are there further systematical differences across regions with high and low shares of jobs that are suitable for working at home?

To tackle these questions, the BIBB-BAuA data is very suitable as it contains detailed information on occupation, earnings, as well as, worker characteristics. Moreover, the data provides information on the region and industry, as well as some information on the employer. Most importantly, and in contrast to related studies such as Dingel and Neiman (2020) or Mongey and Weinberg (2020), we observe workers' responses to survey questions that directly ask about the usage of working at home and to what extent this is done by the worker. Given the fact, that in the current crisis more employers allow their workforce to work from home, whenever this is possible, one might argue that the share of jobs with home work opportunities calculated with these questions is a lower bound and might be higher in the current crisis. To tackle this issue, the data further allows us to use a question where workers indicate if their job is not at all suitable for working at

\footnotetext{
${ }^{1}$ In Germany, the short-time allowance is paid by the Federal Employment Agency and amounts to 60 - $67 \%$ of the former wage rate.
} 
home.

Our analysis provides very strong and robust evidence for a wage premium for jobs with opportunities to work from home. The wage premia vary between 44 percent without any controls and 12 percent in a rich regression with a full set of worker, firm, and task controls as well as fixed effects for industries, regions and detailed job classifications. Hence, workers which should be less affected by the crisis already had an advantage in terms of labor market outcomes before the crisis. This raises concerns that the current crisis increases the wage gap and contributes to a rising inequality if already less privileged workers with jobs not suitable for working at home lose their jobs or suffer from income cuts through short-time allowance.

To see whether there are regional disparities, we compute the share of jobs with the opportunity to work from home across German NUTS2 districts. Here, a clear pattern emerges which indicates a low share of these jobs in Eastern Germany and a much higher share in urban areas of Western Germany. ${ }^{2}$ We further relate the share of workers using the option to work from home in a region to the mean worker earning. Here, we find a very strong positive relation between these two measures. Noting that this is just a correlation, it nevertheless suggests that the current crisis could affect already poorer regions more heavily as a lower share of workers can work from home. In Germany, this could increase the already existing inequality between the eastern and the western part. Finally, we investigate income inequality within NUTS2 regions and relate it to the share of jobs that can be carried out at home. Our results show that the income inequality is systematically higher in those regions with a high share of working from home occupations. Again, this is just a correlation but it raises the concerns that in those regions inequality might even increase as a large share of workers has relatively more crisis-proof jobs.

Our paper is mostly related to recent papers that study opportunities to work from home in light of the recent corona pandemic. Dingel and Neiman (2020) rely on US data and classify the feasibility to work from home using workers' responses to work context stemming from O*NET surveys. They find an overall share of $34 \%$ of US jobs is eligible to be conducted at home and show disparities of this share across cities and industries. Mongey and Weinberg (2020) rely on the measure of Dingel and Neiman (2020) and compare characteristics of workers in the different type of occupations. They show that workers systematically differ across the types of occupations in many characteristics but they do not show a wage premium of working from home at the worker level. While these papers emphasize the importance of workplace characteristics in determining the feasibility of working from home, we show that the wage premium survives even within jobs and after controlling for detailed workplace activities. Moreover, our focus on inequality distinguishes our analysis from these papers.

We structure our paper as follows: Section 2 provides a brief description of the data. In Section 3, we show our main results for a worker-level analysis in Section 3.1 and a regional analysis in Section 3.2. Finally, Section 4 concludes and summarizes the main implications from our study.

\footnotetext{
${ }^{2}$ The NUTS2 districts with the highest share of working from home jobs are Cologne, Darmstadt, Hamburg, and Upper Bavaria. The regions with the lowest share conclude Thuringia, Brandenburg, Saxony-Anhalt, and Chemnitz.
} 


\section{Data}

We use the most recent wave of the BIBB/BAuA Employment Survey which was conducted between October 2017 until April 2018. As in previous waves, the information is based on a random sample of around one-tenth of a percent of the German labor force. Previous waves and survey questions have been used in earlier research, for example by Acemoglu and Pischke (1998), Spitz-Oener (2006), Gathmann and Schönberg (2010), and Becker and Muendler (2015). The data set provides detailed information on worker characteristics, the income, industry, occupation, and workplace properties. What makes the data source especially suitable for our analysis is that the most recent wave includes questions on working from home practices. Specifically, workers are asked if they work for their company - even if only occasionally - from home and how frequently this occurs. Furthermore, workers are asked if their company would allow them to work at home temporarily or if working from home is not possible in their job. We use this information to construct three different measures: (i) WFH - an indicator variable equal to one if the respondent reports to work (occasionally) from home, (ii) WFH-hours - the number of hours working from home, and (iii) No-WFH - an indicator variable equal to one if the job cannot be performed from home. Table 1 provides descriptive statistics for these three measures.

Table 1: Descriptive statistics

\begin{tabular}{lccccc}
\hline \hline & Mean & SD & Min & Max & N \\
\hline WFH & 0.36 & 0.48 & 0 & 1 & 18006 \\
WFH-hours & 7.03 & 7.42 & 1 & 60 & 4459 \\
No-WFH & 0.54 & 0.50 & 0 & 1 & 11448 \\
\hline
\end{tabular}

Source: BIBB-BAuA 2018.

Notes: WFH is an indicator variable equal to one if the respondent reports to work (occasionally) from home. WFH-hours denotes the number of hours working from home. No-WFH is an indicator variable equal to one if the job cannot be performed from home.

While these measures are based on information collected in years prior to COVID-19, they nevertheless provide a good information for the current situation. In Figure 1, we plot our measures for WFH and No-WFH against the mobility trends for places of work provided by Google for the 16 different federal states in Germany. ${ }^{3}$ As can be inferred from the left panel of Figure 1, federal states with a higher share of workers working from home experience a stronger decline in the mobility trend for places of work. Using our alternative measure No-WFH in the right panel, we see that those states with higher employment shares in jobs that cannot be performed from home experience a less pronounced decline in the mobility trend for workplaces. Taking stock, Figure 1 provides some first indication that working from home practices varies at the regional level and that these measures are correlated with the appearance at the workplace in the current crisis.

\footnotetext{
${ }^{3}$ Google prepared this report to provide information on the responses to social distancing guidance related to COVID-19. Here, we use information on mobility trend changes for places of work on March 29, 2020, relative to a baseline value. The full report and further details are available from https://www.gstatic.com/covid19/mobility/ 2020-03-29_DE_Mobility_Report_en.pdf.
} 
Figure 1: Changes in mobility trend for workplaces and working from home
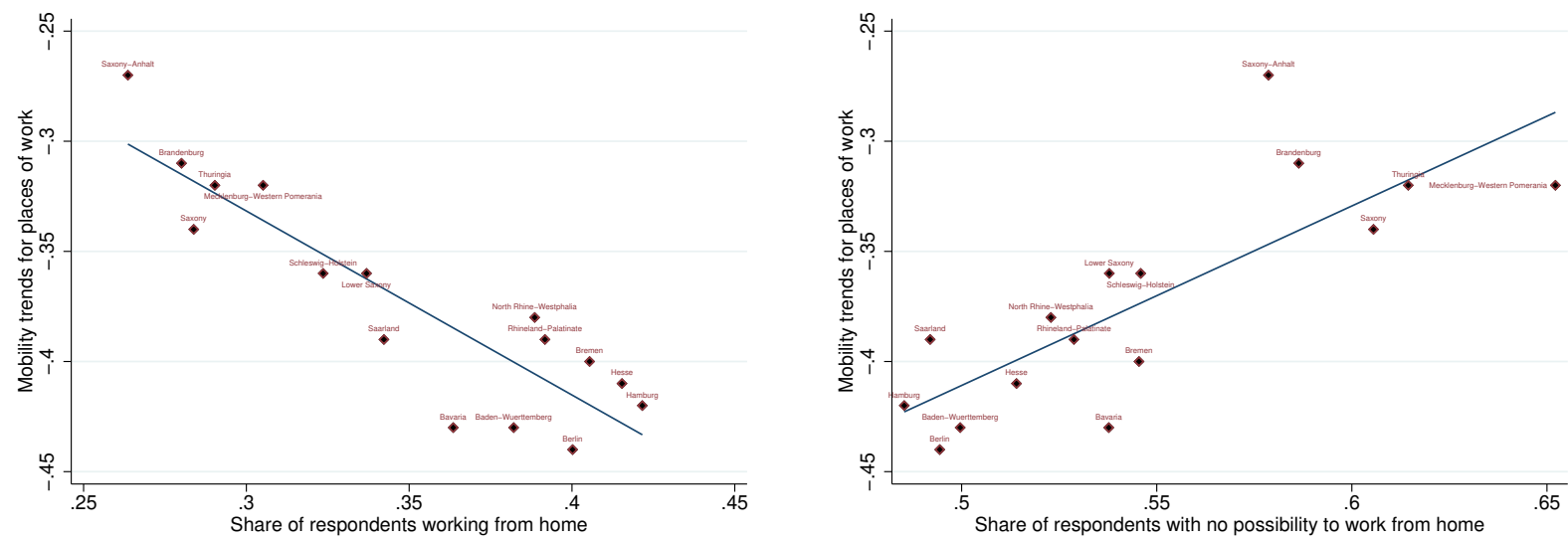

Source: BIBB-BAuA 2018 and Google mobility report.

Notes: The left panel plots the average WFH (an indicator variable equal to one if the respondent reports to work from home) against the change in mobility trend for places of work for the 16 federal states in Germany. The right panel plots the average No-WFH (an indicator variable equal to one if the job cannot be performed from home) against the change in mobility trend for places of work for the 16 federal states in Germany.

In addition to our indicators for working from home practices, we use information on hourly gross wages, education, gender, marriage, age, work experience, migration background, nationality, occupational status, layer, plant-size, industry classification, regional information, job classification, and different workplace characteristics. ${ }^{4}$

\section{Results}

In this section, we begin with an analysis at the level of the worker to analyze wage differences between workers that report to work from home and those that do not report to work from home. In a second step, we then proceed and investigate the regional variation in the opportunities to work from home in Germany and how this is linked to wages and inequality in these regions.

\footnotetext{
${ }^{4}$ Hourly gross wage is computed by using information on the monthly gross wage and weekly working hours. Education is measured in years of schooling. Gender is an indicator variable equal to one if the respondent is female. Marriage is an indicator variable equal to one if the respondent is married. Work experience measures years in employment using the workers age information and the years of education (incl. training). Occupational status is classified into worker, salaried employee and civil servant, which together account for $99 \%$ of total observations in our data with information on home office, and some minor groups (e.g. self-employed person or assisting family member). Layers of hierarchy (workers, supervisors, managers and directors) are based on a classification using ISCO-88 according to Caliendo et al. (2015). The data classifies the worker's company into different size groups (1 person, 2 p., 3 - 4 p., 5 - 9 p., 10 - 19 p., 20 - 49 p., 50 - 99 p., 100 - 249 p., 250 - 499 p., 500 - 999 p., 1000 and more p.). Industry classification is based on the NACE 1.1 for the European Communities and we distinguish between 61 different industries in our data. Regional information is based on the Nomenclature of Territorial Units for Statistics (NUTS2). For the job classification we make use of the 3-digit KldB-92 information that allows us to distinguish between 351 different jobs. Finally, we follow Becker and Muendler (2015) to construct 15 different workplace activities: 1. Manufacture, Produce Goods; 2. Repair, Maintain; 3. Entertain, Accommodate, Prepare Foods; 4. Transport, Store, Dispatch; 5. Measure, Inspect, Control Quality; 6. Gather Information, Develop, Research, Construct; 7. Purchase, Procure, Sell; 8. Program a Computer; 9. Apply Legal Knowledge; 10. Consult and Inform; 11. Train, Teach, Instruct, Educate; 12. Nurse, Look After, Cure; 13. Advertise, Promote, Conduct Marketing and PR; 14. Organize, Plan, Prepare (others' work); 15. Oversee, Control Machinery and Technical Processes.
} 


\subsection{Worker-level analysis}

We aim to investigate if workers that are working from home receive a wage premium. To do so, we regress the log gross daily wage on our indicator variable for working from home. Column 1 in Table 2 reports the coefficient on WFH without using any controls. In columns 2 to 5 , we then include controls for worker characteristics, firm controls, industry and, regional fixed effects. Even after including these controls the wage premium remains significant and sizable. Of course, as emphasized in Dingel and Neiman (2020) or Mongey and Weinberg (2020), the feasibility to work from home depends on the job of a worker and the work context. In columns 6 and 7, we therefore include fixed effects for 3-digit occupation codes and 15 different indicators for activities which workers perform in their job. Looking at the last column, we observe that the wage premium remains significant at the 1\%-level and accounts for around $12 \%$, indicating a sizable wage premium for workers working from home within jobs and controlling for their work context.

Table 2: Working from home and wage income

\begin{tabular}{lccccccc}
\hline \hline & & \multicolumn{3}{c}{ Dependent variable: log gross daily wage } \\
& $(1)$ & $(2)$ & $(3)$ & $(4)$ & $(5)$ & $(6)$ & $(7)$ \\
\hline WFH & $0.440^{* * *}$ & $0.262^{* * *}$ & $0.242^{* * *}$ & $0.223^{* * *}$ & $0.215^{* * *}$ & $0.148^{* * *}$ & $0.121^{* * *}$ \\
& $(0.00835)$ & $(0.00836)$ & $(0.00867)$ & $(0.00880)$ & $(0.00868)$ & $(0.00882)$ & $(0.00885)$ \\
\hline Worker controls & No & Yes & Yes & Yes & Yes & Yes & Yes \\
Firm controls & No & No & Yes & Yes & Yes & Yes & Yes \\
Industry fixed effects & No & No & No & Yes & Yes & Yes & Yes \\
Region fixed effects & No & No & No & No & Yes & Yes & Yes \\
Occupation fixed effects & No & No & No & No & No & Yes & Yes \\
Task controls & No & No & No & No & No & No & Yes \\
\hline Observations & 14650 & 13644 & 11304 & 11239 & 11239 & 11239 & 11239 \\
R-squared & 0.160 & 0.304 & 0.394 & 0.433 & 0.453 & 0.534 & 0.551 \\
\hline \hline
\end{tabular}

Notes: The dependent variable in all columns is the log hourly gross wage. WFH is an indicator variable equal to one if the respondent reports to work (occasionally) from home. Worker controls include education (in years of schooling), indicator variables for gender, married, migrant, foreigner, occupational status, age (-squared), and experience (-squared). Firm controls include the layer of the job and a plant-size measure. Industry fixed effects are based on NACE 1.1. Region fixed effects are based on NUTS2. Occupation fixed effect are based on KldB-92 classification. Task controls include 15 different activities following the definition in Becker and Muendler (2015).

In Table 3, we look at the intensive margin of working from home. We restrict the sample to those workers that report to work from home and regress the log hourly gross wage on the hours working from home (in logs). The table follows the same structure as Table 2. Throughout all columns, the coefficient on WFH-hours is highly significant and positive indicating that workers who work from home to a larger extent also receive higher wages. In a last step to our worker-level analysis, we repeat the analysis from Table 2 but use information if the job is suitable for working at home or not. This is important, as not every worker is working from home in our data (before the COVID-19 outbreak) even though the job might be suitable to do so. Table 4 reveals that workers in those jobs that cannot be performed from home receive a negative wage premium. The effect is significant but less pronounced compared to our analysis in Table 2, indicating a wage discount of 
around $2.3 \%$ in the most stringent specification.

Table 3: Hours working from home and wage income

\begin{tabular}{|c|c|c|c|c|c|c|c|}
\hline & \multicolumn{7}{|c|}{ Dependent variable: log gross daily wage } \\
\hline & $(1)$ & $(2)$ & (3) & (4) & $(5)$ & $(6)$ & $(7)$ \\
\hline \multirow[t]{2}{*}{ log WFH-hours } & $0.0893^{* * *}$ & $0.0566^{* * *}$ & $0.0449 * * *$ & $0.0396 * * *$ & $0.0395^{* * *}$ & $0.0320 * * *$ & $0.0284^{* * *}$ \\
\hline & $(0.00861)$ & $(0.00818)$ & $(0.00833)$ & $(0.00844)$ & $(0.00845)$ & $(0.00866)$ & $(0.00858)$ \\
\hline Worker controls & No & Yes & Yes & Yes & Yes & Yes & Yes \\
\hline Firm controls & No & No & Yes & Yes & Yes & Yes & Yes \\
\hline Industry fixed effects & No & No & No & Yes & Yes & Yes & Yes \\
\hline Region fixed effects & No & No & No & No & Yes & Yes & Yes \\
\hline Occupation fixed effects & No & No & No & No & No & Yes & Yes \\
\hline Task controls & No & No & No & No & No & No & Yes \\
\hline Observations & 3620 & 3481 & 2957 & 2942 & 2942 & 2942 & 2942 \\
\hline R-squared & 0.029 & 0.175 & 0.293 & 0.345 & 0.362 & 0.465 & 0.482 \\
\hline
\end{tabular}

Notes: The dependent variable in all columns is the log hourly gross wage. WFH-hours denotes the number of hours working from home (in logs). Worker controls include education (in years of schooling), indicator variables for gender, married, migrant, foreigner, occupational status, age (-squared), and experience (-squared). Firm controls include the layer of the job and a plant-size measure. Industry fixed effects are based on NACE 1.1. Region fixed effects are based on NUTS2. Occupation fixed effect are based on KldB-92 classification. Task controls include 15 different activities following the definition in Becker and Muendler (2015). The sample is restricted to this workers that report to work (occasionally) from home.

Table 4: No working from home possibility and wage income

\begin{tabular}{|c|c|c|c|c|c|c|c|}
\hline & \multicolumn{7}{|c|}{ Dependent variable: log gross daily wage } \\
\hline & $(1)$ & $(2)$ & $(3)$ & $(4)$ & $(5)$ & $(6)$ & $(7)$ \\
\hline \multirow[t]{2}{*}{ No-WFH } & $-0.167 * * *$ & $-0.113^{* * *}$ & $-0.0932^{* * *}$ & $-0.0680^{* * *}$ & $-0.0651^{* * *}$ & $-0.0372^{* * *}$ & $-0.0228^{* *}$ \\
\hline & $(0.00939)$ & $(0.00903)$ & $(0.00945)$ & $(0.00947)$ & $(0.00931)$ & $(0.00948)$ & $(0.00940)$ \\
\hline Worker controls & No & Yes & Yes & Yes & Yes & Yes & Yes \\
\hline Firm controls & No & No & Yes & Yes & Yes & Yes & Yes \\
\hline Industry fixed effects & No & No & No & Yes & Yes & Yes & Yes \\
\hline Region fixed effects & No & No & No & No & Yes & Yes & Yes \\
\hline Occupation fixed effects & No & No & No & No & No & Yes & Yes \\
\hline Task controls & No & No & No & No & No & No & Yes \\
\hline Observations & 9423 & 8618 & 7076 & 7031 & 7031 & 7031 & 7031 \\
\hline R-squared & 0.033 & 0.179 & 0.274 & 0.337 & 0.368 & 0.478 & 0.498 \\
\hline
\end{tabular}

Notes: The dependent variable in all columns is the log hourly gross wage. No-WFH is an indicator variable equal to one if the job cannot be performed from home. Worker controls include education (in years of schooling), indicator variables for gender, married, migrant, foreigner, occupational status, age (-squared), and experience (-squared). Firm controls include the layer of the job and a plant-size measure. Industry fixed effects are based on NACE 1.1. Region fixed effects are based on NUTS2. Occupation fixed effect are based on KldB-92 classification. Task controls include 15 different activities following the definition in Becker and Muendler (2015).

\subsection{Regional analysis}

In this section, we want to include a regional component into our analysis. Our data set provides regional information at the NUTS2-level for 38 districts in Germany. Since our worker-level analysis 
revealed a clear pattern which indicates that workers with opportunity to work from home earn a wage premium, we want to analyze the distribution of such jobs across regions. Moreover, we are interested in the relationship between the share of jobs with home work opportunities on the one hand, and the average wage as well as the income inequality, on the other hand.

Regional disparities We compute the share of respondents working from home at the NUTS2 regional level and illustrate our results in Figure 2. Here, a darker color indicates a larger share of WFH jobs. Figure 2 reveals a clear pattern of a lower share of jobs with working from home opportunities in the eastern part of Germany whereas this share is highest in urban areas around cities such as Cologne, Darmstadt, Hamburg, and Munich. ${ }^{5}$ The share varies between 22 and 46 percent of occupations. Assuming that jobs with the opportunity to work from home are more crisis-proof, we may conclude that regions are prepared to varying degrees to take up the challenges of the recent crisis.

Figure 2: Working from home in Germany

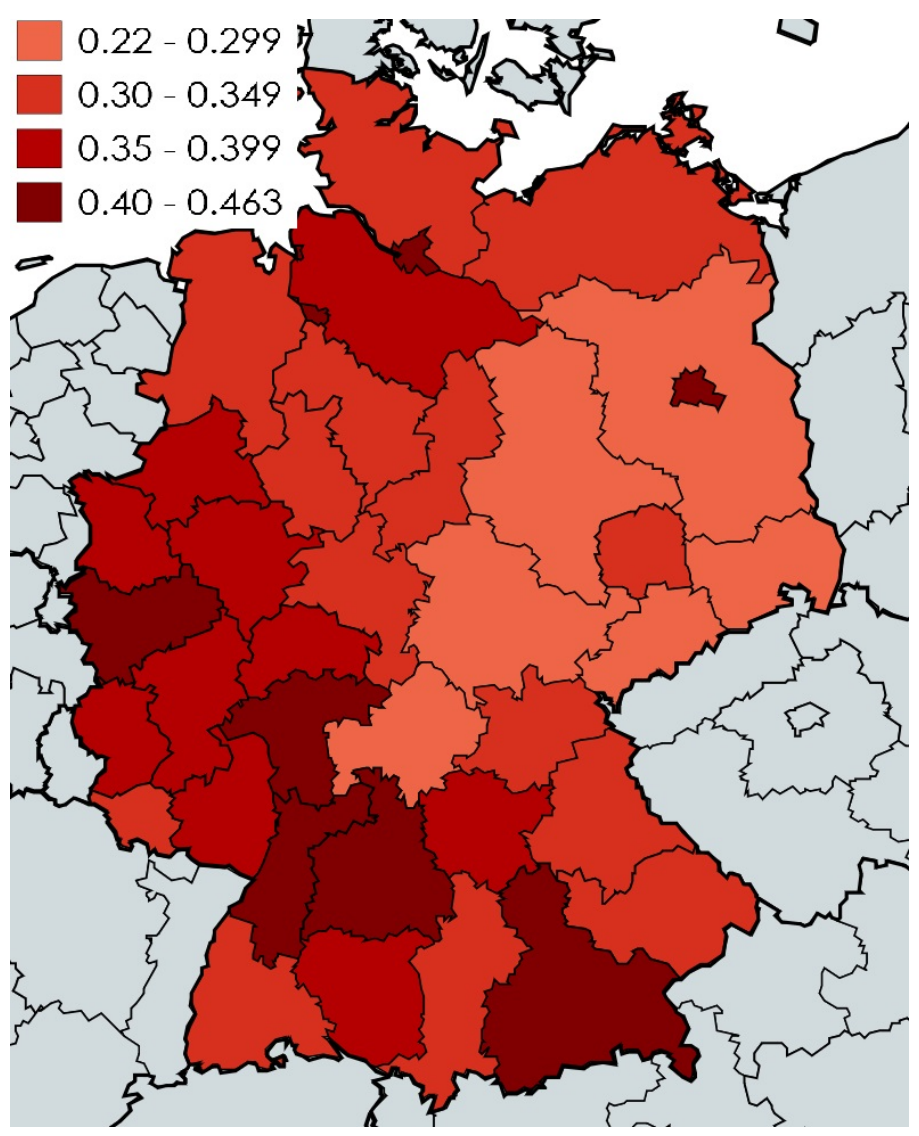

Source: BIBB-BAuA 2018.

Notes: The map illustrates the average share of workers that report to work (occasionally) from home for the 38 different NUTS2 regions in Germany.

\footnotetext{
${ }^{5}$ Table 5 in the Appendix to this paper provides results for all NUTS2 districts in Germany used throughout the subsequent analysis.
} 
Opportunities to work from home and average wages In a next step, we want to investigate the relationship between the share of WFH jobs and the average wage at the NUTS2 regional level. Figure 3 provides a clear picture of a positive relationship between the share of WFH jobs and the average wage rate. Districts with a higher share of jobs with the opportunity to work from home are characterized by a higher average wage rate. This relationship holds true in both panels of Figure 3. While the left-hand side contains the average log hourly wage on the y-axis, the panel on the right-hand side uses average residuals from a Mincer regression with a huge set of controls used in Section 3.1. In the Appendix, Figure 5 makes use of the No-WFH variable which captures jobs that cannot be performed from home. In the light of the recent crisis, this robustness check is important since the actual share of home work opportunities could be higher than it was the case when the survey was conducted. Hence, it is very comforting for our analysis that the clear picture remains the same with a negative relationship between the average wage and the share of jobs that definitely cannot be performed from home.

Figure 3: Working from home and wages in Germany
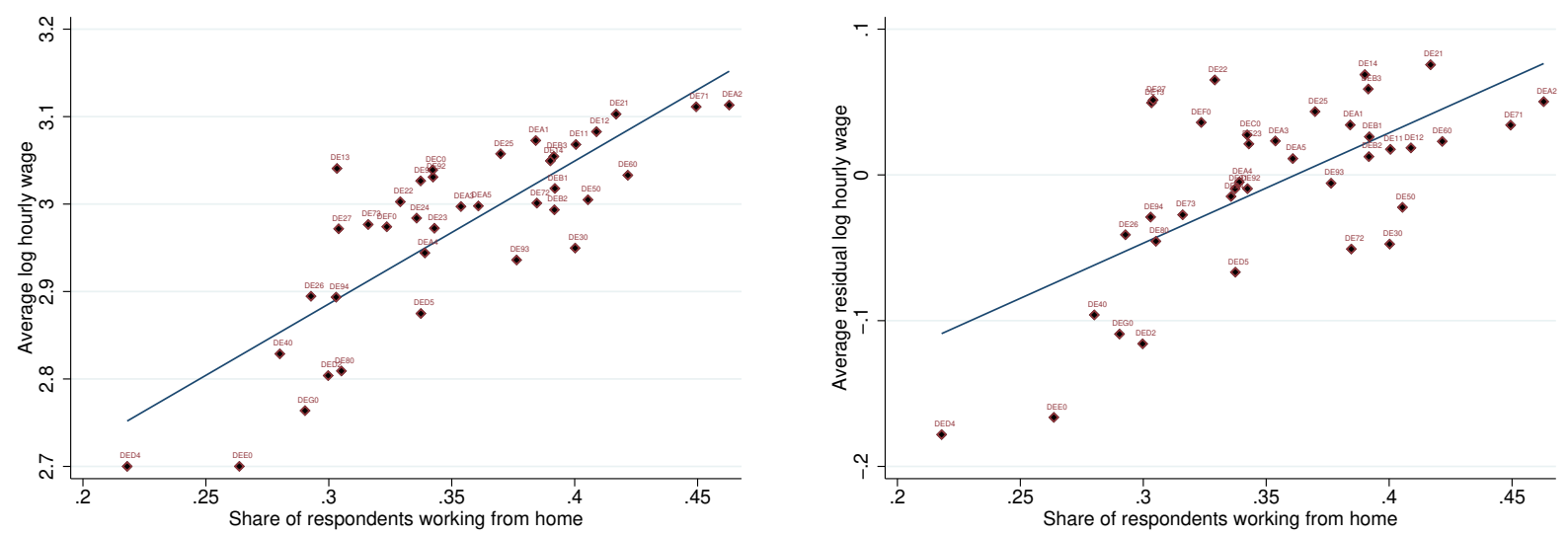

Source: BIBB-BAuA 2018.

Notes: The left panel depicts the average of WFH (an indicator variable equal to one if the respondent reports to work from home) and the average log hourly wage for 38 different NUTS2 regions in Germany. The right panel uses the average log residual wage after running a mincer regression including worker and firm controls, industry and occupation fixed effects and workplace characteristics (see Section 3.1 for details on these variables). Regional codes are described in Table 5 in the Appendix.

Opportunities to work from home and inequality In a final step, we compute the variance of log hourly wages and log wage residuals, respectively. We use these measures to capture the inequality of wages at the regional level and relate it to the share of WFH jobs. Again, we perform a robustness check using the share of No-WFH jobs in Figure 6 of our Appendix. Both panels in Figure 4 show a clear positive relationship. In analogy to the pattern above, the panel on the right-hand side uses the residuals from a rich regression with many controls. Note, that we do not claim causation here as we do not in the patterns above, however, we detect a clear trend that regions with a higher share of WFH jobs are characterized by a higher degree of inequality in terms of wages. 
Figure 4: Working from home and wage inequality in Germany
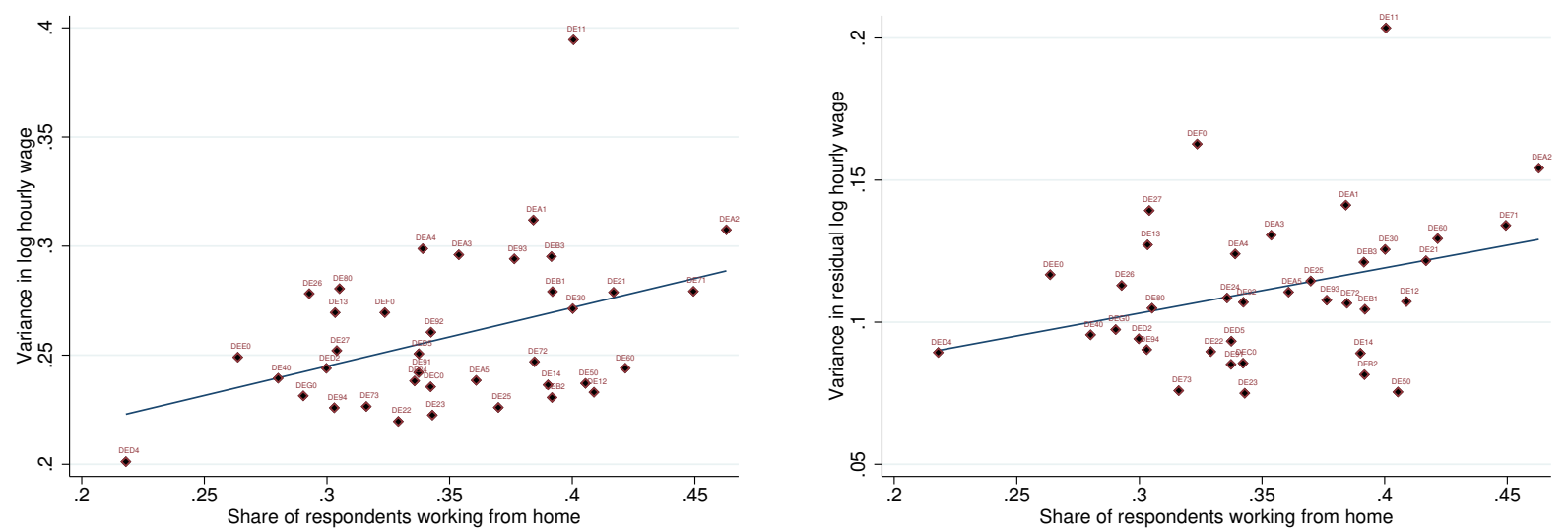

Source: BIBB-BAuA 2018.

Notes: The left panel depicts the average of WFH (an indicator variable equal to one if the respondent reports to work from home) and the variance in log hourly wage for 38 different NUTS2 regions in Germany. The right panel uses the variance of the log residual wage after running a mincer regression including worker and firm controls, industry and occupation fixed effects and workplace characteristics (see Section 3.1 for details on these variables. Regional codes are described in Table 5 in the Appendix.

\section{Implications and conclusion}

Our analysis revealed a clear and stable wage premium for jobs with the opportunity to work from home. This leads us to the conclusion that workers in these jobs were already privileged before the outbreak of the corona crisis. Under the assumption that these kind of jobs seem to be more crisisproof on average, the advantages of these workers could even be more pronounced during and after the current crisis. Since there is widespread scientific consensus, that social distancing is essential to bring the outbreak of the coronavirus under control, policy makers around the globe decided to lockdown whole industries. Hence, it is plausible to assume that in particular workers without the ability to work from home will suffer under those prevention policies. This may lead to a rising pay gap between occupations and works against all efforts to reduce social inequalities. We are aware of the fact, that there are complementarities between jobs with and without the opportunity to work from home. This implies negative spillovers on WFH jobs if their complementary No-WFH jobs cannot be performed any longer during the cirsis. Nevertheless, we believe that the crisis hurts people more in those jobs where the opportunity to work from home does not exist.

Another concern is that regional inequalities may increase in the aftermath of the corona crisis. Indeed, our analysis revealed a clear pattern showing that districts with a higher share of WFH jobs are characterized by a higher average wage rate. We documented a lower share of jobs with working from home opportunities in the eastern part of Germany. More than 30 years after the fall of the Berlin Wall, Eastern Germany still has not closed the gap and is lacking behind Western Germany in terms of GDP, wages, and disposable income of private households. Having in mind our results, the corona crisis could slow down the catch-up process of Eastern Germany. Hence, looking at regional disparities in terms of different types of occupations is central for policy makers in choosing the right economic policies to mitigate the consequences of the crisis. 


\section{References}

Acemoglu, Daron and Jörn-Steffen Pischke, "Why Do Firms Train? Theory and Evidence," Quarterly Journal of Economics, February 1998, 113 (1), 79-119.

Becker, Sascha O. and Marc-Andreas Muendler, "Trade and Tasks: An Exploration Over Three Decades in Germany," Economic Policy, October 2015, 30 (84), 589-641.

Caliendo, Lorenzo, Ferdinando Monte, and Esteban Rossi-Hansberg, "The Anatomy of French Production Hierarchies," Journal of Political Economy, 2015, 123 (4), 809-852.

Dingel, Jonathan and Brent Neiman, "Who Can Work at Home?," Covid Economics, March 2020, 1 (1), 16-24.

Gathmann, Christina and Uta Schönberg, "How General Is Human Capital? A Task-Based Approach," Journal of Labor Economics, January 2010, 28 (1), 1-49.

Mongey, Simon and Alex Weinberg, "Characteristics of Workers in Low Work-From-Home and High Personal-Proximity Occupations," Working Paper, Becker Friedman Institute March 2020 .

Spitz-Oener, Alexandra, "Technical Change, Job Tasks, and Rising Educational Demands: Looking Outside the Wage Structure," Journal of Labor Economics, 2006, 24 (2), 235-270.

\section{Data:}

This paper uses data from the BIBB/BAuA Employment Survey of the Working Population on Qualification and Working Conditions in Germany 2018, doi: 10.7803/501.18.1.1.10. The Survey was conducted by the Federal Institute for Vocational Education and Training (BIBB), and the Federal Institute for Occupational Safety and Health (BAuA). The data access was provided via a Scientific-Use-File of the Data Research Centre at the Federal Institute for Vocational Training and Education (BIBB-FDZ). 


\section{Appendix}

Figure 5: No working from home possibility and wages in Germany
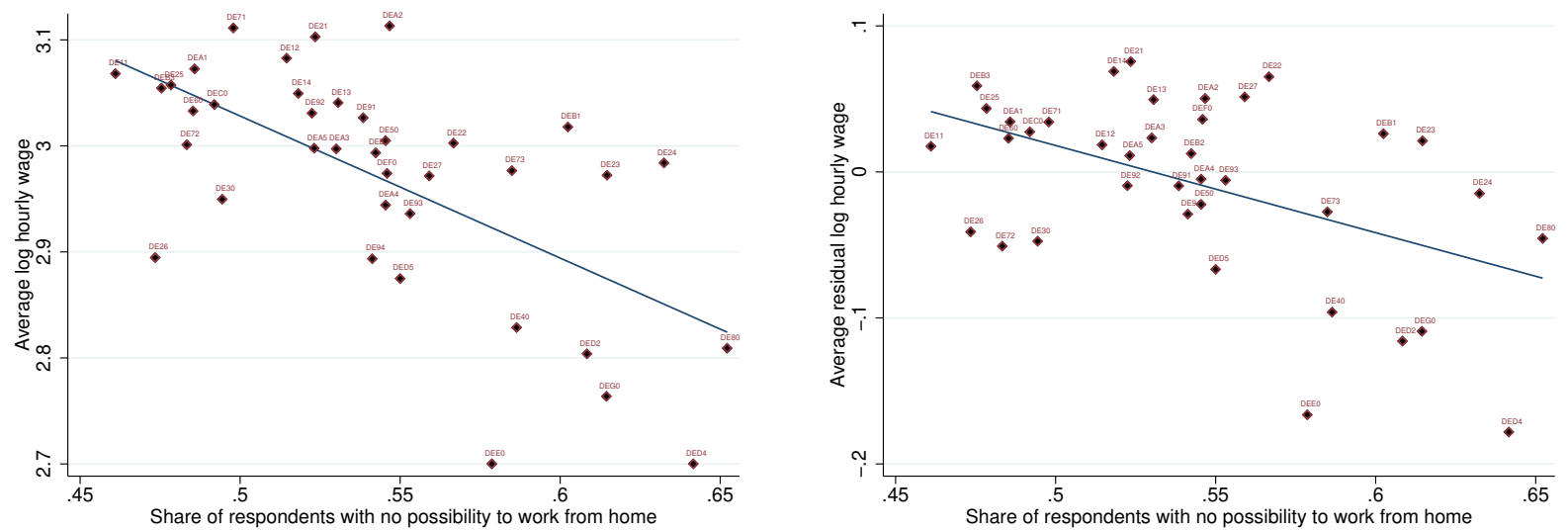

Source: BIBB-BAuA 2018.

Notes: The left panel depicts the average of $\mathrm{No}-\mathrm{WFH}$ (an indicator variable equal to one if the job cannot be performed from home) and the average log hourly wage for 38 different NUTS2 regions in Germany. The right panel uses the average log residual wage after running a mincer regression including worker and firm controls, industry and occupation fixed effects and workplace characteristics (see Section 3.1 for details on these variables. Regional codes are described in Table 5 in the Appendix.

Figure 6: No working from home possibility and wage inequality in Germany
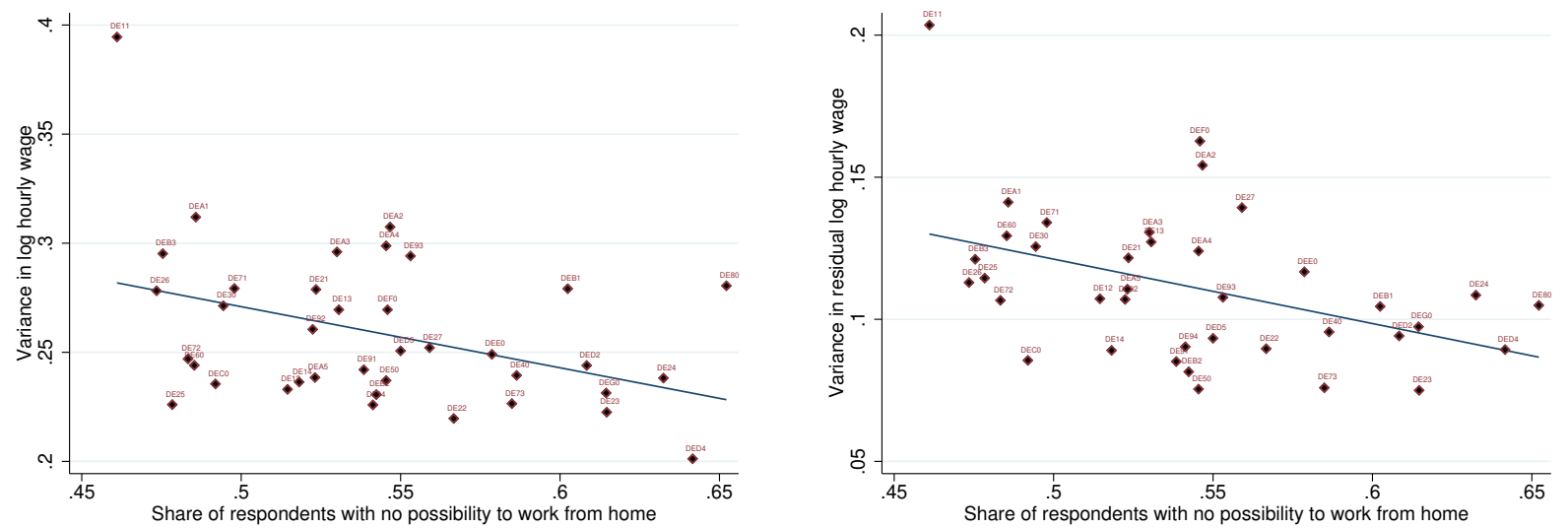

Source: BIBB-BAuA 2018.

Notes: The left panel depicts the average of No-WFH (an indicator variable equal to one if the job cannot be performed from home) and the variance of the log hourly wage for 38 different NUTS2 regions in Germany. The right panel uses the variance of the log residual wage after running a mincer regression including worker and firm controls, industry and occupation fixed effects and workplace characteristics (see Section 3.1 for details on these variables. Regional codes are described in Table 5 in the Appendix. 
Table 5: Summary statistics for NUTS2 regions in Germany

\begin{tabular}{|c|c|c|c|c|c|c|c|}
\hline NUTS2 & NUTS2 Name & WFH & No-WFH & wage & residual wage & Var(wage) & Var (residual wage) \\
\hline DEF0 & Schleswig-Holstein & 0.32 & 0.55 & 2.97 & 0.04 & 0.27 & 0.16 \\
\hline DE60 & Hamburg & 0.42 & 0.49 & 3.03 & 0.02 & 0.24 & 0.13 \\
\hline DE91 & Statistical region Brunswick & 0.34 & 0.54 & 3.03 & -0.01 & 0.24 & 0.09 \\
\hline DE92 & Statistical region Hanover & 0.34 & 0.52 & 3.03 & -0.01 & 0.26 & 0.11 \\
\hline DE93 & Statistical region Lueneburg & 0.38 & 0.55 & 2.94 & -0.01 & 0.29 & 0.11 \\
\hline DE94 & Statistical region Weser-Ems & 0.30 & 0.54 & 2.89 & -0.03 & 0.23 & 0.09 \\
\hline DE50 & Bremen & 0.41 & 0.55 & 3.00 & -0.02 & 0.24 & 0.08 \\
\hline DEA1 & Duesseldorf & 0.38 & 0.49 & 3.07 & 0.03 & 0.31 & 0.14 \\
\hline DEA2 & Cologne & 0.46 & 0.55 & 3.11 & 0.05 & 0.31 & 0.15 \\
\hline DEA3 & Muenster & 0.35 & 0.53 & 3.00 & 0.02 & 0.30 & 0.13 \\
\hline DEA4 & Detmold & 0.34 & 0.55 & 2.94 & 0.00 & 0.30 & 0.12 \\
\hline DEA5 & Arnsberg & 0.36 & 0.52 & 3.00 & 0.01 & 0.24 & 0.11 \\
\hline DE71 & Darmstadt & 0.45 & 0.50 & 3.11 & 0.03 & 0.28 & 0.13 \\
\hline DE72 & Giessen & 0.38 & 0.48 & 3.00 & -0.05 & 0.25 & 0.11 \\
\hline DE73 & Kassel & 0.32 & 0.58 & 2.98 & -0.03 & 0.23 & 0.08 \\
\hline DEB1 & Statistical region Koblenz & 0.39 & 0.60 & 3.02 & 0.03 & 0.28 & 0.10 \\
\hline DEB2 & Statistical region Trier & 0.39 & 0.54 & 2.99 & 0.01 & 0.23 & 0.08 \\
\hline DEB3 & Statistical region Rhine-Hesse-Palatinate & 0.39 & 0.48 & 3.05 & 0.06 & 0.30 & 0.12 \\
\hline DE11 & Stuttgart & 0.40 & 0.46 & 3.07 & 0.02 & 0.39 & 0.20 \\
\hline DE12 & Karlsruhe & 0.41 & 0.51 & 3.08 & 0.02 & 0.23 & 0.11 \\
\hline DE13 & Freiburg & 0.30 & 0.53 & 3.04 & 0.05 & 0.27 & 0.13 \\
\hline DE14 & Tuebingen & 0.39 & 0.52 & 3.05 & 0.07 & 0.24 & 0.09 \\
\hline DE21 & Upper Bavaria & 0.42 & 0.52 & 3.10 & 0.08 & 0.28 & 0.12 \\
\hline DE22 & Lower Bavaria & 0.33 & 0.57 & 3.00 & 0.07 & 0.22 & 0.09 \\
\hline DE23 & Upper Palatinate & 0.34 & 0.61 & 2.97 & 0.02 & 0.22 & 0.08 \\
\hline DE24 & Upper Franconia & 0.34 & 0.63 & 2.98 & -0.01 & 0.24 & 0.11 \\
\hline DE25 & Middle Franconia & 0.37 & 0.48 & 3.06 & 0.04 & 0.23 & 0.11 \\
\hline DE26 & Lower Franconia & 0.29 & 0.47 & 2.89 & -0.04 & 0.28 & 0.11 \\
\hline DE27 & Swabia & 0.30 & 0.56 & 2.97 & 0.05 & 0.25 & 0.14 \\
\hline DEC0 & Saarland & 0.34 & 0.49 & 3.04 & 0.03 & 0.24 & 0.09 \\
\hline DE30 & Berlin & 0.40 & 0.49 & 2.95 & -0.05 & 0.27 & 0.13 \\
\hline DE40 & Barndenburg & 0.28 & 0.59 & 2.83 & -0.10 & 0.24 & 0.10 \\
\hline DE80 & Mecklenburg-Western Pomerania & 0.31 & 0.65 & 2.81 & -0.05 & 0.28 & 0.10 \\
\hline DED4 & Directorate region Chemnitz & 0.22 & 0.64 & 2.70 & -0.18 & 0.20 & 0.09 \\
\hline DED2 & Directorate region Dresden & 0.30 & 0.61 & 2.80 & -0.12 & 0.24 & 0.09 \\
\hline DED5 & Directorate region Leipzig & 0.34 & 0.55 & 2.87 & -0.07 & 0.25 & 0.09 \\
\hline DEE0 & Saxony-Anhalt & 0.26 & 0.58 & 2.70 & -0.17 & 0.25 & 0.12 \\
\hline DEG0 & Thuringia & 0.29 & 0.61 & 2.76 & -0.11 & 0.23 & 0.10 \\
\hline
\end{tabular}

Source: BIBB-BAuA 2018

Notes: The table reports averages for WFH (an indicator variable equal to one if the respondent reports to work from home), No-WFH (an indicator variable equal to one if the job cannot be performed from home), log gross hourly wages, residual wages after running a Mincer regression (see Sections 3.2 for details) and variance of log gross hourly wages and residual wages for the 38 different NUTS2 regions in Germany. 